\title{
The development of health technology assessment in Brazil
}

\author{
David Banta \\ Professor Emeritus, University of Maastricht
}

Rosimary T. Almeida

Federal University of Rio de Janeiro

Objectives: The aim of this study was to describe the developing health technology assessment (HTA) activities in Brazil, both historically and in the present day.

Methods: This report is a descriptive analysis based on personal experiences of the authors and on selected literature.

Results: Interest in HTA in Brazil began in the mid-1980s. Several seminars and consultations were held, often with invited foreign participants. A cadre of people with knowledge and expertise in HTA was gradually developed. In 2003, several policies were developed by the federal government of Brazil to encourage HTA and base clinical, management, and policy decisions on HTA. During the past 5 years, institutional development has been rapid in government, private companies (mainly prepaid health plans), academia, and research institutes. Further policy changes are needed to maximize the impact of these developments. Nevertheless, although the growing network of HTA programs will have a considerable impact on Brazilian health care, further institutional development could stimulate this change.

Conclusions: It would be desirable if the Federal Ministry of Health of Brazil were to proceed to develop a national agency for HTA.

Keywords: Health technology assessment, History, Health planning, Brazil

Brazil is the largest country in South America, with a population of approximately 186 million people and a land mass approximately the same size as that of the United States. Brazil is a developing country, but is one of the richest in that category, and is now a member of the Organization for Economic Cooperation and Development (OECD), an organization of developed countries.

Brazil began to develop a comprehensive universal healthcare system in the 1980s (3). The Constitution of 1988 furnished a set of principles and directions for the system as well as consolidating all publicly funded healthcare programs. The Constitution developed the Unified Health System (SUS), which provides universal access to comprehensive health care for all residents of Brazil. Since that time, several policy initiatives have strengthened the system, but it remains, in theory, a system that provides access to all citizens (and other residents) to a comprehensive set of health services.

\section{FINANCING AND ORGANIZATION OF BRAZILIAN HEALTH CARE SERVICES}

There are three major sources of funding for Brazilian health care: government, largely the federal government, through taxes and social security; companies, mostly prepaid health plans; and out-of-pocket payments. Out-of-pocket payments remain high, approximately one-third of health expenditures, private health insurance, on the other hand, gives rather low coverage, with only $25 \%$ of the population enrolled, compared to an OECD average of approximately 33\%. This has produced serious equity problems, contrary to the principles stated in the Constitution (16). The richer part of the population tends to use the private services.

Under the law, the three levels of the public sectorthe Ministry of Health, the State Health Secretariats, and the Municipal Health Secretariats-should participate in a network that is linked, regionalized, and decentralized, with 
unified leadership at each level of government. This unified health system is known by its Brazilian acronym SUS. Activities and services should be provided according to the policy and guidelines approved by the Health Councils, composed of representatives of the government, health professionals, service providers, and users (15).

Under health reforms in 1996, Brazil established a public program of universal access, to comprehensive care provided by municipalities, but financed by the states and the federal government. Therefore, every resident is entitled to free comprehensive care. The total SUS expenses are approximately 90 billion reais (Brazilian currency).

Some data about SUS: $70 \%$ of population depend on the services ( $\sim 130$ million people); 2.3 billion outpatient medical procedures/year; 300 million medical attendances/year; 11.3 million of hospitalized patients; 2 million births/year; 15 thousand organ transplants; and a decrease of $50 \%$ in infant mortality, since SUS was established.

However, the Constitution allows private services. Private services essentially duplicate the services of the public sector. A significant number of private providers furnish care to both the public system and the so-called private supplementary system. The total expenses of this system are approximately 42 billion reais.

\section{PROBLEMS WITH HEALTH TECHNOLOGY IN BRAZIL}

As with essentially all developing countries, Brazil has depended on imports to obtain health technology (4). For example, in 1978, Brazil imported pharmaceutical products worth US $\$ 215$ million, while exporting only US $\$ 40$ million in such products (18). A similar picture was seen with medical devices: in 1981, Brazil imported approximately US\$32 million in medical equipment from the United States, with very little in the way of exports (5).

Furthermore, it was estimated in the early 1980s that $30 \%$ of all the medical equipment in Brazil was out of service due to lack of maintenance or spare parts (5). A publication from Pan American Health Organization/World Health Organization (PAHO/WHO) observed, "In practice (technology transfer) has consisted in the uncritical acceptance and indiscriminate, wholesale acquisition of technologies rather than of knowledge, without any regard for their actual usability, suitability, efficiency, or effectiveness" (17).

Skills and knowledge had to come from the United States and Europe. There were relatively few medical journals published.

With time, problems in health technology have been increasingly addressed. However, one effect of the developments that Brazil has seen is that the expense of such imports has grown greatly. The economic development of Brazil in the past 30 years has meant that the country is now increasingly able to produce its own medical products. However, new drugs (under patent) must still be imported.
The medical scenario has changed since the 1990s. The number of medical schools and graduate courses increased greatly after 1990. Brazil is second in the world in number of medical schools (167), only exceeded by India with 202 schools (12). The major problem at this time is the quality of some schools, which were opened without defined or set criteria. The present situation is that more control is being taken by the Minister of Education after a long series of protests from the medical societies.

With time, there has been a great increase in the number of Brazilian medical publications.

With the developments toward a comprehensive health services for all Brazilians, several problems were increasingly seen in the 1990s, including the following (8): (i) lack of scientific evidence to support the use of widely used procedures; (ii) substantial variation in the use of technologies without improvement in health results; (iii) technologies that have been proven to have no effect on health, or deleterious effects, were widely used; (iv) technologies were often used outside of the conditions and indications in which they had been shown to be effective.

These technological problems were seen along with a continuous increase in health-related expenditures, rapid technological change, and changes in the demographic characteristics of the Brazilian population, with the growth in chronic diseases and diseases of aging (7).

During the 1990s, it also became apparent that evaluation of the implications of health technologies was inadequate, with resulting inequalities in technological distribution. The frequent close relationships between industry and healthcare providers led to numerous conflicts of interest (1).

\section{DEVELOPMENT OF INTEREST IN HEALTH TECHNOLOGY ASSESSMENT}

The first formal event in Brazil concerning health technology assessment (HTA) was a week-long international seminar on the subject in Brasilia DC in 1983, under the sponsorship of PAHO/WHO and the Brazilian government. Several wellknown Brazilians, as well as representatives of other Latin American countries and the United States, took part in the meeting. The meeting examined HTA from several different aspects, concentrating on policy issues such as questionable efficacy of many health technologies, problems of costs and cost-effectiveness, and problems of technology transfer.

Following this seminar, several events concerning HTA were held under the sponsorship of the Oswaldo Cruz Foundation-Fiocruz and Ministry of Health, and organized by Leticia Krauss Silva. David Banta, Michael Drummond, and others took part in seven or eight such meetings, held in both Rio de Janeiro and Brasilia DC. They began with general overviews of HTA, but later dealt with such subjects as policy implications of HTA and also carried out reviews and discussions of ongoing Brazilian research projects related to HTA. Each meeting showed a growth in the number of 
people interested in HTA, as well as an increasing sophistication among attendees at such meetings.

An important event concerning the history of HTA in Brazil was the decision of Leticia Krauss Silva to gain a PhD from Birmingham University, England, under the supervision of Prof. Michael Drummond. Dr. Krauss Silva studied the outcomes of a neonatal intensive care unit in Rio de Janeiro and showed that its outcomes were far behind those of such units in North America and Europe (21). Why these results were found was not entirely clear, because the facilities and equipment of the unit were equivalent to those in other countries. One possible issue was the fact that the physicians involved had more than one position, and did not dedicate themselves full-time to the intensive care unit (21). This study concerned "effectiveness," showing that health technology must be examined in terms of effectiveness, and not only in terms of efficacy (that is, in the actual conditions of use in a particularly setting). Although this is always true, it may be an observation more applicable in developing countries.

At the same time, initiatives in HTA research were developed in academic institutions, such as the Federal University of Rio de Janeiro, the State University of São Paulo, and others.

\section{DEVELOPMENT OF HTA AS A POLICY TOOL IN BRAZIL}

These early efforts finally began to produce real results in the year 2000, when a series of policy initiatives brought HTA into active life in federal government institutions in Brazil. Specific to health technology, a National Council on Science, Technology and Innovation was formed in 2004, with representation of all relevant parts of government, plus many representatives of civil society (6). A national policy on science, technology, and innovation in health was published in 2005 (9). At approximately the same time, the Permanent Work Group on Health Technology Assessment (GT ATS) was established. The GT ATS was formed by representatives of the Department of Pharmaceutical Assistance, the Department of Health Economics, the Secretariat of Health Attention, the Secretariat of Health Vigilance, the Secretariat of Management of the Health Work, the Secretariat Executive, the Brazil's National STD and AIDS Programme, the National Health Surveillance Agency (Anvisa), and the National Health Private Insurance Agency (ANS). This Work Group has the mission to identify the technologies considered strategic and high priority for the Brazilian Public Health System, whether already incorporated or not. Those determined to be a high priority should become the subject of HTA studies.

That was followed by an administrative rule on incorporation of technologies into the unified health system (SUS) (6). The National Council discussed the need for a more formal method and system for assessing health technology, and then proposed a National Policy on Health Technology Management in 2006 (10). This proposal emphasized the role of health technology assessment in the management of health technology. A coordinating role was assigned to the Department of Science, Technology and Strategic Inputs (DECIT), part of the Federal Ministry of Health. DECIT was expected to coordinate a wide range of HTA activities, as well as the growing network of HTA programs. DECIT thus became the lead program in HTA in Brazil (11).

DECIT is not an agency for HTA, but it can fund original research and systematic reviews and it can also establish standards for assessment. For example, in 2008, the Department published a document on HTA (in English) (7), and in 2007, it published a set of methodological guidelines for HTA (8). DECIT also gives technical advice to a National Committee of the Minister of Health, which is responsible for recommending what technologies to incorporate in the public health system (SUS). Finally, DECIT should develop activities for training and cooperation with teaching and research institutions, as well as public health managers (7). The priority themes for research in HTA are determined by the Permanent Work Group on HTA.

The DECIT team in 2008 included 15 in-house consultants, from a wide range of professional backgrounds. The HTA activities are also supported by approximately 40 external consultants. In 2008, DECIT had published 31 systematic reviews and had 10 being evaluated, had 12 health technology economic appraisals being reviewed, and had completed approximately 60 short appraisal reviews per year (7).

\section{POLICIES TOWARD HEALTH TECHNOLOGY}

Aside from the policies developing for HTA, Brazil has few direct policy tools to manage health technology. However, the National Drug Policy was approved in 1998, with the purpose of ensuring safety, efficacy, and quality of drugs, as well as the promotion of rational use and access for the population to essential products. Its implementation presupposes decentralized management of resources, based on a national list of essential drugs and a set of essential products whose supply is mandatory. Production and marketing of pharmaceuticals is regulated by the federal, state, and municipal health secretariats comprising Anvisa.

There is a National Register of Drug and Health Devices in the market under the responsibility of Anvisa (2). In addition, Anvisa also has a well-established regulation of pharmaceutical prices. The criteria applied in this process include epidemiology of disease, treatment options, description of the pharmaceutical to be evaluated, efficacy and safety data, economic evaluation (including local data, i.e., cost data at least, cost/quality-adjusted life-year if possible), and budget impact.

Brazil has developed an active program to promote generic drugs, and also provides drugs at subsidized prices. 
It has been stated that similar regulations are needed for other inputs, including medical equipment and medical procedures. The distribution of drugs is dependent on a local government organization. However, devices are often bought and offered to the population, mainly by private services, without any rules on distribution and access.

Another important policy is definition of covered services in the public system. The rules for incorporation of technology in SUS apply to all technologies (drug, devices, procedures, and programs), and they are evaluated by the same criteria as pharmaceuticals: epidemiology of disease, treatment options, description of the pharmaceutical to be evaluated, efficacy and safety data, economic evaluation (including local data, i.e., cost data at least, cost/qualityadjusted life-year if possible), and budget impact. As mentioned above, DECIT gives technical support to a national committee, which is formed by one representative of three Ministry of Health secretariats, Anvisa, and ANS.

\section{GROWTH OF THE NETWORK OF HTA PROGRAMS}

The policies toward HTA have had an enormous impact on the situation with HTA in Brazil. In principle, HTA should be encouraged throughout the healthcare system (20).

One important development is to encourage HTA in the prepaid health plans (the "Supplementary System." Regulation of this sector began in 2000, with the establishment of ANS, a part of the Ministry of Health for this purpose. ANS has formed a Task Force for Technology Management, as part of its responsibility to ensure attention to the public interest in the private healthcare system. ANS formed a Division of HTA in 2005. In principle, prepaid plans are now required to be involved in HTA, and they should only provide services after clear evidence of efficacy is available (13).

Several HTA new groups have developed in research institutes and universities. For example, Rio Grande do Sul, a state in southern Brazil, has developed a Brazilian Independent HTA Group in the Federal University of Rio Grande do Sul, which has particularly focused on certain drugs for rare diseases, but which also has worked on methodological guidelines for HTA and on clinical guidelines for pharmaceuticals for the Ministry of Health (19).

\section{DISCUSSION}

The development of HTA in Brazil is highly interesting for several reasons. One is how the dedication of a few individuals to the ideas of HTA first developed a "critical mass" of people with interest and expertise in HTA, and eventually led to significant changes in Brazilian health care.

Brazil has been internationally involved with HTA since the early seminars in HTA in the 1980s. By 2006, the DECIT had joined International Network of Agencies for Health Technology Assessment (INAHTA). In 2008, there were
15 individual members from Brazil in the HTAi Annual Meeting.

However, the story is still developing. The Brazilian healthcare system still has many problems, including many inequities and problems with incorporation of technology $(14 ; 16)$. Historically, relations between industry and healthcare managers and clinicians have often been close, which has produced many conflicts of interest and resulted in many questionable decisions (1).

The problems with health technology in Brazil are still rather acute, for these and other reasons. In effect, the entire healthcare system needs to be involved in assessing health technologies and removing those with unknown and unproven efficacy or even frank lack of efficacy. There are many people in the system resistant to the changes suggested in the development of HTA. In effect, the struggle to develop an equitable, accessibly healthcare system based on efficacious and cost-effective technology is still under way and has far to go.

One problem is that the regulatory structure concerning health technology is relatively weak. This means that HTA must have an effect on the thinking and practice of many practitioners and managers, always a difficult challenge.

Also, the HTA policies and institutions described in this study are still new and are not very strong. In truth, development has been very rapid during the past 5 years, but it will take time to develop a sufficient number of people with good training and expertise in HTA and its many ramifications. A positive development would be to develop a national agency for HTA, based on the work of DECIT. Probably that will come in the next few years.

Therefore, the basic message from HTA in Brazil is that a good beginning has been made, but that considerable further development is necessary.

\section{CONTACT INFORMATION}

David Banta, MD, MPH (HD.Banta@ orange.fr), 9 route de Bragelogne, 10210 Villiers-le-Bois, France

Rosimary T. Almeida, PhD, MSc (rosal@peb.ufrj.br), Associate Professor, Department of Biomedical Engineering, Federal University of Rio de Janeiro, Av. Horácio Macedo 2030, Centro de Technologia, COPPE, Rio de Janeiro, 21941-914 Brazil

\section{REFERENCES}

1. Almeida R. Evaluation of technologies in health. Health in Brazil; Contributions towards an agenda of priorities for research (in Portuguese). Brasilia DC: Ministry of Health; 2004.

2. Anvisa. National Health Surveillance Agency. http://www. anvisa.gov.br/eng/index/htm (accessed November 20, 2008).

3. Banta D. Medical technology and developing countries: The case of Brazil. Int J Health Serv. 1986;16:363-373.

4. Banta D. The transfer of medical technology in developing countries: The case of Brazil. In: Rutten FFH, Reiser SJ, eds. 
The economics of medical technology. Berlin: Springer-Verlag; 1988:16-24.

5. Banta D. The uses of modern technologies: Problems and perspectives for industrialized and developing countries. Bull Pam Am Health Organ. 1984;18:139-150.

6. Brazilian Ministry of Health. Administrative rule 7115271152/GM. Incorporation of technologies into the Unified Health System (SUS). Brasilia DC: Ministry of Health; 2006.

7. Brazilian Ministry of Health. Health technology assessment. Brasilia: Ministry of Health; 2008.

8. Brazilian Ministry of Health. Methodological guidelines for appraisals on health technology assessment for the Ministry of Health of Brazil. Brasilia: Ministry of Health; 2007.

9. Brazilian Ministry of Health. National policy on science, technology and innovation in health (PHCTISO). Brasilia DC: Ministry of Health; 2005.

10. Brazilian Ministry of Health. National policy on health technology management (PNGTS). Brasilia DC Office Gazette \#191. 2006. http://portal.saude.gov.br/portal/saude/visualizar_texto. cfm?idtxt=25187\&janela=1 (accessed November 20, 2008).

11. Brazilian Ministry of Health. Rule \# 2.587/30th October 2008. http://bvsms.saude.gov.br/bvs/saudelegis/gm/2008/prt2587_ 30_10_2008.html (accessed November 20, 2008).

12. Brazilian Medical Association. Only India superceded Brazil in the number of medical school. In: News of Brazilian Medical Association, 5 June 2007. http://www.amb.org.br/mc_ noticias1_abre.php3?w_id=2768 (accessed December 30, 2008).
13. Dias R, Pereira F, Mesquita A, et al. HTA as a support to technological incorporation in the Brazilian Supplementary Health System, a new challenge to health care managers. Presentation to the Health Technology Assessment International (HTAi) 2007, Barcelona, Spain.

14. Dominquez U, Soares S. Analysis of equity in Brazilian health system financing. Health Aff. 2007;26:73-82.

15. ECORYS. Brazil health care and reimbursement decisions (draft report). Rotterdam: the Netherlands; 2008.

16. Organization for Economic Cooperation and Development (OECD). Economic survey of Brazil 2005, Better targeting of government social spending. Paris: OECD.

17. Pan American Health Organization. Health for All by the Year 2000: Strategies. PAHO Official Document 179. Washington, DC; PAHO; 1980.

18. Pan American Health Organization. Policies for the production and marketing of essential drugs. Technical discussions of the 29th Directing Council. PAHO document CD29/DT/1. Washington DC: PAHO; 1983.

19. Picon P. Brazilian independent HTA group. Brazil: Porto Alegre; 2008.

20. Serruya S, Costa J, Albuquerque I, Tolentino M. Health technology assessment: The Brazilian institutional experience in 2005. Paper prepared for INAHTA. Stockholm, Sweden: INAHTA; 2006.

21. Silva LK. "Avaliação custo-efetividade de níveis de complexidade crescente de assistência neonatal no Rio de Janeiro." Cadernos de Ciência e Tecnologia, Rio de Janeiro: CC\&T; 1992:50-57. 